\title{
Erken puberte açısından değerlendirilen obez ve obez olmayan kız çocuklarının klinik, laboratuvar ve radyolojik verilerinin karşılaştırılması
}

\author{
Comparison of clinical, laboratory and radiological data of obese and non-obese girls \\ evaluated for precocious puberty
}

Deniz Özalp Kızılay, Hale Ünver Tuhan

\begin{abstract}
Özet
Amaç: Erken puberte (EP) etiyolojisinde, genetik faktörler sorumlu tutulsa da beslenme ve çevresel faktörler de suçlanmaktadır. Kızlarda EP ile obezite prevalansının artması arasında ilişki olduğu gösterilmiştir. Fazla kilolu ve obez çocukların, genellikle büyümede ve seksüel olgunlaşmada hızlanma ile birlikte ileri kemik yaşına (KY) sahip olduğu bildirilmiştir. Çalışmamızda, meme gelişimi ile başvuran ve EP açısından tetkik edilen obez ve obez olmayan kız çocuklarının klinik, laboratuvar ve radyolojik bulgularını karşılaştırmayı amaçladık.

Gereç ve yöntem: Çalışmaya 3-8 yaş aralığında, meme dokusu nedeniyle çocuk endokrin polikliniğine başvuran ve EP ayırıcı tanısı için gonadotropin salgılatıcı hormon $(\mathrm{GnRH})$ uyarı testi yapılan 50 obez ve fazla kilolu, 50 normal kilolu kız olgu alındı. Olguların takvim yaşı (TY), vücut ağırlığı standart deviasyon skoru (SDS), boy SDS, $\mathrm{KY}, \mathrm{KY}-\mathrm{TY}$ farkı ( $\triangle \mathrm{KY}$-TY), bazal ve uyarılmış folikül stimülan hormon $(\mathrm{FSH})$, luteinizan hormon (LH), östradiol, pik LH/FSH oranı, pelvik ultrasonografi ile ultrasonla değerlendirilen uterus uzun çapı, uterus ve over volümleri kaydedildi.

Bulgular: Obez ve fazla kilolu olguların, boy SDS ve $\triangle K Y$-TY değerleri istatistiksel olarak anlamlı yüksek (sırasıyla $p=0,001$ ve $p=0,02)$, KY istatistiksel olarak anlamlıya yakın yüksek bulundu $(p=0,05)$. Obez olmayan olgularda bazal FSH değeri anlamlı yüksek saptandı $(p=0,03)$. GnRH test yanıtlarında, Santral EP (SEP) tanı oranı obez olmayan olgularda (\%26), obez olgulara (\%16) göre daha yüksek saptandı, iki grup arasında anlamlı fark yoktu.

Sonuç: Obez olgularda, Boy SDS ve $\triangle K Y$-TY değerlerini daha yüksek ancak SEP tanı oranını düşük saptadık. Obez kızlarda kompansatuar hiperinsülinemi, insülin direnci, endokrin bozucular ve androjenler gibi altta yatan mekanizmalar, KY ilerlemesine ve pubertal karakteristik değişikliklere katkıda bulunarak SEP öngörüsünde yanıltıcı olabilir.
\end{abstract}

Anahtar kelimeler: Erken puberte, kız çocuk, obezite.

Özalp Kızılay D, Ünver Tuhan H. Erken puberte açısından değerlendirilen obez ve obez olmayan kız çocuklarının klinik, laboratuvar ve radyolojik verilerinin karşılaştırılması. Pam Tıp Derg 2020;13:487-494.

\begin{abstract}
Purpose: Although genetic factors are responsible for the etiology of precocious puberty (PP), nutrition and environmental factors are also blamed. A correlation between PP and prevalence of obesity have been shown in girls. Overweight and obese children generally have advanced bone age (BA) with accelerated growth and sexual maturation. We aimed to investigate the differences in terms of clinical, laboratory and radiological findings between obese and non-obese girls who presented with breast development and were examined for PP.

Materials and methods: Fifty overweight and obese and fifty normal weight girls (3-8 years of age) who were admitted to the pediatric endocrine clinic for breast development and investigated for PP were included. Chronological age (CA), body weight standard deviation score (SDS), height SDS, BA, BA-CA difference ( $\triangle B A$ $\mathrm{CA})$, basal and stimulated follicle stimulating hormone $(\mathrm{FSH})$, luteinizing hormone $(\mathrm{LH})$, estradiol and peak $\mathrm{LH} / \mathrm{FSH}$ ratio were recorded. Uterine long diameter, uterine and ovarian volumes were evaluated by pelvic ultrasonography.

Results: Height SDS and $\triangle \mathrm{BA}-\mathrm{CA}$ of obese subjects were found statistically higher $(p=0.001, p=0.02$ respectively). BA was almost significantly higher $(p=0.05)$. Baseline $\mathrm{FSH}$ were higher in non-obese subjects $(p=0.03)$. There was no difference between the groups in $\mathrm{GnRH}$ test. $16 \%$ obese and $26 \%$ non-obese subjects were diagnosed as central PP (CPP).

Conclusion: Despite higher height SDS and $\triangle B A-C A$ values, the rate of CPP was low in obese group. Underlying mechanisms such as compensatory hyperinsulinemia, insulin resistance, endocrine disruptors and androgens
\end{abstract}

Deniz Özalp Kızılay, Uzm. Dr. İzmir Çiğli Bölge Eğitim Hastanesi, Çocuk Endokrin Kliniği, İzmir, Türkiye, e-posta: drdenizkizilay@gmail.com (orcid.org/0000-0003-4529-4404) (Sorumlu Yazar)

Hale Ünver Tuhan, Dr. Öğr. Üye. Akdeniz Üniversitesi Tıp Fakültesi Hastanesi, Çocuk Endokrin Kliniği, Antalya, Türkiye, e-posta: halenvr@ hotmail.com (orcid.org/0000-0002-7637-9630) 
may contribute to bone age progression and pubertal characteristic changes. Those can be misleading for CPP predicting.

Key words: Precocious puberty, girl child, obesity.

Özalp Kızılay D, Ünver Tuhan H. Comparison of clinical, laboratory and radiological data of obese and nonobese girls evaluated for precocious puberty Pam Med J 2020;13:487-494.

\section{Giriş}

Erken puberte (EP), sekonder cinsiyet karakterlerinin toplum ortalamasına göre erken gelişimi ile karakterizedir. Santral erken puberte (SEP) ve periferik erken puberte (PEP) olarak sınıflandırılabilir [1]. Kızlarda EP sekiz yaşından önce meme gelişiminin başlangıcı ile karakterizedir [2]. SEP, hipotalamo-pitüitergonadal (HPG) aksın erken aktivasyonundan kaynaklanır ve gonadotropin salgılatıcı hormon $(\mathrm{GnRH})$ ile uyarılan gonadal fonksiyon ile başlar. Erken puberte, erken ve hızı iskelet gelişimi ve epifizlerin erken kapanması ile çocukların nihai boylarının genetik potansiyeline göre daha kısa olmasına yol açmaktadır [3]. Erken puberte etiyolojisinde primer olarak genetik faktörler sorumlu tutulsa da beslenme durumu, obezite ve endokrin bozucu kimyasallara maruz kalma gibi çevresel faktörlerin de etkili olduğu bilinmektedir [4].

Çocukluk döneminde obezite son yıllarda önemli bir sağlık sorunu haline gelmiştir. Obezite, pubertal hormonlarda değişiklik ve puberte başlangıcı gibi pubertal gelişimin birçok yönünü etkileyebilir [5]. Fazla kilolu ve obez çocukların, genellikle büyümede ve seksüel olgunlaşmada hızlanma ile birlikte ileri kemik yaşına (KY) sahip olduğu bildirilmiştir [6]. Son zamanlardaki veriler, ergenlik gelişiminin erken zamanlaması veya daha hızlı ilerlemesinin, daha yüksek vücut kütle indeksi (VKI) ile ilişkili olduğunu, ayrıca bu bireylerin ergenlik ve erişkinlik döneminde daha fazla kilo alma riski ile karşı karşıya olduklarını göstermektedir [7]. Adipozite, SEP başlangıcının metabolik bir bekçisi olarak düşünülmektedir ve $\mathrm{GnRH}$ puls üretecinin erken aktivasyonu ile ilişsilendirilmiştir [4].

Araştırmalar, ergenlik çağının daha erken başlaması ile kızlarda obezite prevalansının artması arasında bir ilişki olduğunu göstermektedir [8]. Bununla birlikte, EP ile kızlarda obezite arasındaki ilişkiler halen net değildir. Çalışmamızda, meme dokusu nedeniyle çocuk endokrin kliniğine başvuran ve
EP açısından tetkik edilen obez ve obez olmayan kız çocuklarının klinik, laboratuvar ve radyolojik verilerinin karşılaştıııması amaçlanmıştır.

\section{Gereç ve yöntem}

Çiğli Bölge Eğitim Hastanesi çocuk endokrin polikliniğine, izole meme gelişimi nedeniyle başvuran ve çocuk endokrin uzmanı tarafından yapılan fizik muayenede meme gelişimi Tanner evre 2 olarak değerlendirilen [9], EP ayırıcı tanısı için $\mathrm{GnRH}$ uyarı testi endikasyonu konulan 50 fazla kilolu ve obez, 50 normal kilolu, 3-8 yaş aralığındaki kız olgular çalışmaya dahil edildi. Çalışma, hastaların dosya kayıtlarının geriye yönelik incelenmesi ile yapıldı. Çalışma protokolü, Behçet Uz Çocuk Hastanesi Tıbbi Etik Komitesi tarafından onaylandı ve Helsinki Deklarasyonu kapsamında yapıldı.

Dosya kayıtlarından, hastaların başvuru sırasındaki takvim yaşı (TY), vücut ağırığı (VA), VA standart deviasyon skoru (SDS), boy SDS, VKI SDS, KY, KY TY farkı ( $\triangle K Y-T Y$ ), bazal ve $\mathrm{GnRH}$ uyarı testi ile uyarılmış zirve folikül stimülan hormon (FSH), LH, E2, pik LH/FSH oranı, pelvik ultrasonografi ile değerlendirilen uterus uzun çapı, uterus ve over volümleri kaydedildi. Lipomasti olarak değerlendirilen hastalar, dosya kayıtlarında eksik veri saptanan olgular, meme gelişimine pubik ve/veya aksiller kıllanmanın eşlik ettiği olgular, genetik ya da hormonal (hipotiroidi, cushing vs) nedenlere bağlı obezitesi olan, kronik hastalığı ve/veya ilaç kullanımı olan, laboratuvar veya radyolojik olarak karaciğer, renal, tiroid, adrenal patolojilere bağlı PEP tanısı alan veya hipofizer ya da intrakraniyal patolojilere bağıı organik SEP tanısı alan olgular çalışma dışında bırakııdı.

Antropometrik ölçümler sabah aç karnına ve ölçümü yapılan çocuğun ayakkabıları ve üst giysileri çıkarımış haldeyken yapıldı. Hastaların boyları $0,1 \mathrm{~cm}$ ölçme hassasiyetine sahip Harpenden stadiometresi (Holtain Limited, Crymych, Dyfed, U.K) ile, VA'ları 0,1 $\mathrm{kg}$ hassasiyetle ölçen SECA (isim olup, açılımı 
yoktur) (GMBH \& CO KG Hamburg, Germany) tartısı ile değerlendirildi. VKi; VA $(\mathrm{kg}) / \mathrm{Boy}(\mathrm{m})^{2}$ formülü ile hesaplandı [10]. VA SDS, boy SDS ve VKI SDS değerleri Olcay Neyzi verileri kullanılarak hesaplandı. VKI'i 85-95 persantil arasında olan olgular fazla kilolu, $>95 p$ olan olgular obez olarak kabul edildi [11]. FSH ve LH değerleri immünokemiluminesans (ICMA) yöntemi ile ölçülmüştür. $K Y$ değerlendirmesi, sol el bilek grafisi ile Greulich ve Pyle atlasına göre değerlendirilmiştir [12]. Pubertal evreleme, inspeksiyon ve palpasyon ile pediatrik endokrinolog tarafından Marshall ve Tanner yöntemine göre yapılmıştır [9]. GnRH uyarı testi endikasyonları, meme gelişimi ile birlikte KY/TY $>1$ olması, Bazal LH > 0,1 mlU/mL, E2 > 12 $\mathrm{pg} / \mathrm{mL}$ ve/veya pelvik ultrasonografi bulguları pubertal (Uterus hacmi $>2 \mathrm{~mL}$ / uterus uzun aksı $>34 \mathrm{~mm}$, over hacmi > $2 \mathrm{~mL}$ ) olması idi. $\mathrm{GnRH}$ uyarı testi, saat 08-10:00 aralığında, $2,5 \mu \mathrm{g} / \mathrm{kg}$ (en yüksek $100 \mu \mathrm{g}$ ) LHRH'nın (LHRH Ferring ampul, Ferring İlaç San. ve Tic. Ltd.) intravenöz verilmesini takiben 30 . ve 60 . dakikada venöz kan alınarak yapılmıştır. Bazal LH değeri $>1,1$ IU/L [13] veya $\mathrm{GnRH}$ testi ile elde edilen pik LH $>5 \mathrm{IU} / \mathrm{L}$ olan olgular SEP olarak değerlendirildi. [14].

İstatistiksel analiz SPPS 21.0 (SPSS Inc., Chicago, IL, USA) programı kullanılarak yapıldı. Verilerin homojen dağılımı Kolmogorov-Smirnov testi kullanılarak değerlendirildi. Grupların karşılaştırılmasında normal dağılanlarda Student $\mathrm{t}$ testi (ortalama değer \pm standart sapma), normal dağılmayanlarda Mann-Whitney $U$ testi (ortanca değer / minimum-maksimum) ve grup oranlarının karşılaştırıımasında ki-kare testi uygulandı. Kategorik değişkenler \% olarak gösterildi. $P$ değerinin $<0,05$ olması istatistiksel olarak anlamlı kabul edildi.

\section{Bulgular}

Çalışmaya alınma kriterlerini karşılayan 50 obez ve fazla kilolu, 50 normal kilolu toplam 100 kız olgunun verileri kaydedildi. Olguların klinik, laboratuvar ve radyolojik özellikleri Tablo 1' de sunulmuştur.

Obezolgular 3,1-8yaş aralığındaiken, normal kilolu olgular 3,7-8 yaş aralığında idi. Gruplar arasında yaş dağılımı açısından istatistiksel fark saptanmadı $(p=0,8)$. Gruplar, antropometrik veriler açısından karşılaştıııldığında, beklenildiği gibi, obez grubun ağırlık SDS, VKi SDS ve VKI persantil düzeyleri anlamlı olarak yüksekti (sırasıyla $p<0,001, p=0,001, p<0,001$ ). Obez grubun ayrıca boy SDS ortalaması da normal kilolu gruba göre anlamlı düzeyde yüksek saptandı (sırasıyla, $1,4 \pm 1,1$ ve $0,74 \pm 0,9$, $p=0,001$ ). Obez hastaların ortanca KY'si 8,5 (2,5-11) yıl, obez olmayan hastaların da 7,8 $(2,2-11)$ yıl idi. Obez grupta, normal kilolu gruba göre KY'yi istatistiksel olarak anlamlıya yakın ileri saptandı $(p=0,05)$. Obez grupta $\Delta K Y-T Y$ istatistiksel olarak anlamlı düzeyde yüksek saptandı $(p=0,001)$.

Gruplar, laboratuvar değişkenleri açısından karşılaştırıldığında bazal FSH normal kilolu grupta anlamlı olarak yüksek saptandı $(p=0,03)$. Gruplar arasında bazal LH, bazal E2, uyarılmış pik LH ve pik LH/FSH oranı açısından istatistiksel anlamlı fark saptanmadı $(p>0,05)$.

Ultrasonografik değerlendirme sonucunda, iki grup arasında uterus uzun çapı ölçümü ve uterus, sağ over ve sol over hacimleri arasında istatistiksel olarak anlamlı fark saptanmadı $(p>0,05)$.

SEP tanısı alan olguların sayısı normal kilolu grupta, obez gruba göre daha yüksek oranda saptandı [sırasıyla, 13 olgu (\%26) ve 8 olgu (\%16)], iki grup arasında istatistiksel anlamlı fark yoktu $(p=0,22)$ (Tablo 2$)$. 
Tablo 1. Obez ve obez olmayan kız çocuklarının klinik, laboratuvar ve radyolojik verilerinin değerlendirilmesi.

\begin{tabular}{|c|c|c|c|}
\hline Değişkenler & $\begin{array}{l}\text { Obez ve Fazla } \\
\text { Kilolu Grup } \\
n=50\end{array}$ & $\begin{array}{l}\text { Normal Kilolu } \\
\text { Grup } \\
n=50\end{array}$ & $p$ değeri \\
\hline Takvim Yaşı (yıl) & $7,2(3,1-8)$ & $7(3,7-8)$ & $0.8^{a}$ \\
\hline Ağırlık SDS & $2,2 \pm 0,8$ & $0,4 \pm 0,6$ & $<0,001^{b}$ \\
\hline Boy SDS & $1,4 \pm 1,1$ & $0,74 \pm 0,9$ & $0,001^{b}$ \\
\hline VKI SDS & $1,9 \pm 0,6$ & $0,1 \pm 0,7$ & $<0,001^{b}$ \\
\hline VKİ Persantil & $97(85-99,9)$ & $60(8,9-84,7)$ & $<0,001$ \\
\hline Bazal FSH & $1,58(0,35-12)$ & $2(0,47-6,4)$ & $0,03^{a}$ \\
\hline Bazal LH & $0,1(0,1-1,8)$ & $0,1(0,1-0,6)$ & $0,88^{a}$ \\
\hline Bazal E2 & $5(4,3-46,9)$ & $5(5-92)$ & $0,67^{a}$ \\
\hline Uyarılmış pik LH & $2,94(0,7-13,2)$ & $2,95(0,5-16,9)$ & $0,35^{a}$ \\
\hline Pik LH/FSH oranı & $0,22(0,08-1,4)$ & $0,25(0,03-1,5)$ & $0,35^{a}$ \\
\hline Kemik Yaşı (yıl) & $8,5(2,5-11)$ & $7,8(2,2-11)$ & $0,05^{a}$ \\
\hline$\Delta \mathrm{KY}-\mathrm{TY}$ & $1,34(-1,75-3,2)$ & $1(-1,5-3,1)$ & $0,02^{a}$ \\
\hline Uterus uzun çapı (mm) & $31,6 \pm 7,8$ & $29 \pm 6,4$ & $0,1^{\mathrm{b}}$ \\
\hline Uterus hacmi (mL) & $7,5(2,5-40,9)$ & $7,3(2,7-66,5)$ & $0,96^{a}$ \\
\hline Sağ over hacmi (mL) & $1,3(0,1-8,1)$ & $1,4(0,1-6,2)$ & $0,85^{\mathrm{a}}$ \\
\hline Sol over hacmi (mL) & $1,3(0,1-5,7)$ & $1,3(0,1-6,2)$ & $0,95^{a}$ \\
\hline
\end{tabular}

a Mann-Whitney U testi, ortanca değer (minumum-maksimum)

${ }^{\mathrm{b}}$ Student T-test, ortalama değer \pm standart sapma

SDS, standart deviasyon skoru; VKI, vücut kütle indeksi; FSH, folikül stimülan hormon;

LH, luteinizan hormon; $\mathrm{E}_{2}$, östradiol; KY, kemik yaşı; TY, takvim yaşı;

$\Delta K Y-T Y$, kemik yaşı takvim yaşı farkı.

Tablo 2. Gonadotropin salgılatıcı hormon uyarı testinin değerlendirilmesi.

\begin{tabular}{llll}
\hline $\begin{array}{l}\text { GnRH Uyarı Testi } \\
\text { Yanıtları }\end{array}$ & $\begin{array}{l}\text { Obez ve Fazla } \\
\text { Kilolu Grup } \\
\mathrm{n}=50\end{array}$ & $\begin{array}{l}\text { Normal Kilolu } \\
\text { Grup } \\
\mathrm{n}=50\end{array}$ & p değeri \\
\hline Pubertal (SEP) & $8(\% 16)$ & $13(\% 26)$ & 0,22 \\
Prepubertal (PT) & $42(\% 84)$ & $38(\% 74)$ & \\
\hline
\end{tabular}

GnRH, Gonadotropin salgılatıcı hormon; SEP: santral erken puberte; PT, prematür telarş.

\section{Tartışma}

Ergenlik başlangıç bulguları iyi bilinsede, zamanlaması değişkendir. Artan kanıtlar, obezitenin kızlarda erken cinsel gelişim ile yakından ilgili olduğunu göstermektedir [7, 15]. Atay ve ark. [16], 4-8 yaşındaki kızlarda yaptıkları çalışmada, farklı VKi SDS seviyeleri ile erken telarş oluşumu arasında güçlü bir ilişki bulmuştur. Kaplowitz ve ark. [15], Amerika'da yaptıkları bir çalışmada, daha yüksek VKI'nin erken pubik kıllanma ve meme gelişimi intimalinin artmasıyla ilişkili olduğunu gözlemlemiştir. Erken puberte gelişiminde KY ileriliği ve büyümede hızlanma görülmektedir
[6]. Bu durum erişkin nihai boyda kayba neden olduğundan EP'nin erken tanı ve tedavisi önemlidir.

Literatürde, fazla kilolu çocuklarda, normal kilolu çocuklara kıyasla, hızlanmış cinsel olgunlaşmanın yanı sıra doğrusal büyüme ve genellikle eşlik eden ileri $K Y$ gözlendiği bildirilmiştir [17]. Erken çocukluk döneminde hızlı kilo alımına sıklıkla boy hızındaki ve KY ilerlemesindeki artışın eşlik ettiği [18] ve obez çocuklarda KY'nin, TY'yi anlamlı olarak aştığı [19] bulunmuştur. Obez çocuklar, yaşlarına göre genellikle hızlanmış doğrusal büyüme ile ilişkili olarak uzun boyludurlar [20]. Russel ve ark. 
[21], 252 çocukta KY ve TY arasındaki farkın, VKi, yağsız vücut kitlesi ve çift enerjili $X$-ışını absorpsiyometrisi ile değerlendirilen yağ kitlesi ile anlamlı bir şekilde ilişkili olduğunu bildirmiştir. Doğumdan 18 yaşına kadar 521 denekte KY'nin değerlendirildiği çalışmada, obez veya fazla kilolu deneklerde daha ileri düzeyde iskelet olgunlaşması olduğu gösterilmiştir [22]. Meme dokusu varlığı nedeniyle EP açısından obez ve obez olmayan çocukları değerlendirdiğimiz çalışmamızda, biz de literatürle uyumlu olarak, obez kızların ortalama boy SDS'sini daha yüksek ve TY'ne göre KY'lerini daha ileri saptadık. Bu bulgular istatistiksel olarak anlamlı düzeydeydi. Ayrıca obez grubun KY'sini de kontrol grubuna göre anlamlıya yakın düzeyde yüksek saptadık. İleri $\mathrm{KY}$, endişe verici bir bulgudur, çünkü hızlanmış kemik olgunlaşması sonuçta boy kısalığına neden olabilir. Gerçekten de, uzun süreli bir çalışmada, çocukluk döneminde fazla kilolu veya obez olan bireylerin, o dönemde nispeten daha uzun olduğu, ancak daha sonra genç yaşlarında daha az boy uzamalarının olduğu gösterilmiştir [23]. Obez grupta TY'ye göre ileri $K Y$ saptamamıza rağmen buna neden olabileceği düşünülen E2 seviyelerini [24] değerlendirdiğimizde, gruplar arasında bir fark saptamadık. Bu durum, E2 testimizin daha düşük aralıklardaki hassasiyetten yoksun olmasından kaynaklanıyor olabilir. Bu açıklama ile tutarlı olarak Klein ve ark. [25], daha hassas bir analiz kullanıldığında obez ve zayıf çocuklarda E2 seviyelerinin KY ile ilişkili olduğunu göstermiştir. Ayrıca gruplar arasında kanda bakılan E2 seviyeleri arasında farklılık bulunmamasının nedeni, obez çocuklarda meme dokusuna neden olan E2 üretiminin doku düzeyinde gerçekleştiği, böylece dolaşımdaki E2 seviyelerinde bir artış tespit edilemediği [18], görüşüyle de açıklanabilir.

Çalışmamızda, obez kızlarda kontrol grubuna göre SEP için anlamlı olan ileri KY'ye rağmen, $\mathrm{GnRH}$ uyarı testi yanıtları karşılaştırıldığında iki grup arasında SEP görülme olasılığı açısından anlamlı bir fark gözlenmedi. Obez grupta (\%16), kontrol grubuna (\%26) göre SEP tanı oranı daha düşük saptandı. Kilolu kızlarda telarşın, GnRH-gonadotropin ekseninin merkezi aktivasyonu ile ilişkili olup olmadığı henüz bilinmemektedir [26]. Vücut kütle indeksi ile $\mathrm{GnRH}$ test yanıtları arasındaki ilişki bazı araştırmalarda analiz edilmiştir [27,28], ancak sonuçlar tartışmalıdır. Son zamanlarda yapılan çalışmalarda, ergenlikte en erken hormonal değişiklik olarak gösterilen uyku sırasında başlayan LH artışlarının, çok yüksek VKI' leri olan sağlıklı kızlarda köreldiği gösterilmiştir [29, 30]. Lee ve ark. [31], obez ve obez olmayan SEP tanısı alan kızlarda yaptıkları çalışmada, aşırı kilolu kızların, GnRH testi ile uyarılmış LH tepe değerlerinin ve LH / FSH oranlarının daha düşük olduğu ve kilo ile tepe LH seviyelerinin negatif ilişki gösterdiği yönünde iki önemli bulgu ortaya koymuştur. Lee ve ark. [32] yaptıkları başka bir çalışmada, idiyopatik SEP'li kızlarda obezitenin LH sekresyonuna etkisini araştırmış ve erken pubertal evrede artan VKI ile azalmış LH piki arasında pozitif bir ilişki tanımlamıştır. Roth ve ark.'nın [33] yaptığı çalışmada, obez kızlar, gonadorelin stimülasyonuna, normal kilolu kızlara göre daha düşük LH yanıtı vermiştir. VKI artışının azalmış LH düzeyleri ile ilişkili olduğu mekanizmalar belirsizdir. Östrojen ergenliğin başlaması ve ilerlemesinde önemli bir role sahiptir. Obez bireylerde aşırı yağ dokusuna bağlı artan östrojen seviyeleri [34] ve erken ergenlik döneminde $\mathrm{GnRH}$ sekresyonunun seks steroidlerinden kaynaklanan negatif geri bildirimlere karşı son derece hassas olması [35], çalışmamıza dahil edilen obez olgulardaki gonadorelin stimülasyonuna körelen LH yanıtını ve düşük SEP tanı oranını açıklayabilir. $\mathrm{Bu}$ çalışmada, E2 seviyeleri normal kilolu çocuklarda ve obez çocuklarda anlamlı olarak farklı olmasa da, obez grupta $\mathrm{GnRH}$ stimülasyonu ile SEP tanı oranının daha düşük olması kısmen doku düzeyinde ölçülemeyen ancak meme dokusu oluşumuna neden olan artmış östrojen düzeyinin negatif geri besleme etkisini yansıtıyor olabilir.

LHdüzeyleri, ergenliğin sonrakiaşamalarında yükselme eğiliminde iken FSH, ergenliğin erken aşamalarında yükselir [36]. Bizim çalışmamızda da, SEP oranı daha yüksek saptanan obez olmayan grupta, LH düzeyleri açısından gruplar arasında henüz anlamlı bir fark oluşmamasına rağmen, pubertenin erken aşamasında daha belirgin arttığı bilinen FSH düzeyleri anlamlı olarak daha yüksek saptanmıştır.

Meme dokusunun değerlendirmesi klasik olarak Tanner evrelemesi [9] kullanılarak fizik muayene ile yapılır, bu nedenle özneldir. Meme dokusu, obez çocuklarda yağ dokusu ile karışabilmektedir, bu nedenle bu çocuklar gereksiz yere EP açısından tetkik 
edilebilmektedir. Meme ultrasonografisi, meme gelişimini belirlemek için rutin bir tetkik değildir. Bazen, glandüler doku varlığını belirleme konusunda şüpheleri olan klinisyenler tarafından tercih edilebilir. Obez çocuklarda KY gelişimi daha ileri düzeyde ve ayrıca ergenlik öncesi ve erken ergenlik dönemlerinde E2 ve androjen seviyeleri normal kilolu akranlarına göre daha yüksek olabilir [37]. Bu sonuçlar, SEP öngörüsünde yanıltıcı olabilir. Bu nedenle, obezite varlığında pubertal değerlendirme için, daha objektif kriterlere intiyaç vardır. Çalışmamızda meme dokusu ile prezente olan, ileri $\mathrm{KY}$ ve artmış E2 düzeyi nedeniyle $\mathrm{GnRH}$ testi yapılmasına karar verilen obez kızlarda, SEP tanı oranının oldukça düşük saptanması bu gerekliliği desteklemektedir.

$\mathrm{Bu}$ çalışmanın kesitsel, geriye dönük tasarımı ve küçük örneklem büyüklüğü ile ilgili bazı kısıtlamaları vardır. Ayrıca, SEP olarak kabul edilmeyen ancak tepe LH seviyesi 5 IU / L'ye yakın olan olgular SEP grubu ile önemli oranda örtüşebilir. Son olarak, çalışmamızın sonuçlarının nedensellik ilişkisini ortaya koymak için insülin, leptin, SHBG ve androjenler gibi metabolik profil ve hormonal parametrelerin değerlendirildiği prospektif planlanmış kapsamlı çalışmalara intiyaç vardır.

Sonuç olarak, obez ve obez olmayan kızlar arasında EP görülme olasılığı açısından fark bulunmamıştır. Obez kızlarda kompansatuar hiperinsülinemi, insülin direnci, endokrin bozucular ve androjenler gibi altta yatan biyolojik mekanizmalar, KY ilerlemesine ve pubertal karakteristik değişikliklere katkıda bulunarak SEP öngörüsünde yanıltıcı olabilir. Bu grupta SEP ayırıcı tanısında dikkatli olunmalıdır. Bu çalışma, endokrin polikliniğine pubertal bulgularla başvuran özellikle obez olguların çok azında SEP saptanması ve hastaların tanı aşamasında iyi değerlendirilmesi gerektiğini vurgulaması açısından önemlidir. Diğer taraftan, obez çocuklarda hızlanmış epifiziyel büyüme plağı olgunlaşması ve ileri $\mathrm{KY}$ ergenliğin başlamasına yol açan nöroendokrin olayları tetikleyebilir [20]. Bu nedenle, artmış SEP risk grubunu oluşturmaları açısından meme dokusu ile başvuran obez kızların yakın takibinin yapılması önemlidir.

Çıkar ilişkisi: Yazarlar çıkar ilişkisi olmadığını beyan eder.

\section{Kaynaklar}

1. Çayır $Y$, Çayır A. Birinci basamakta erken puberteli çocuğa yaklaşım. Tıp Araştırmaları Dergisi 2013;11:14.

2. Carel JC, Léger J. Clinical practice. Precocious puberty. N Engl J Med 2008;358:2366-2377. https://doi. org/10.1056/NEJMcp0800459

3. Sağsöz N, Orbak Z, Tan H. Precocious puberty in girls. T Klin J Gynecol Obst 1999;9:67-78.

4. Burt Solorzano CM, McCartney CR. Obesity and the pubertal transition in girls and boys. Reproduction 2010;140:399-410. https://doi.org/10.1530/REP-100119

5. Wang $Y$, Lobstein T. Worldwide trends in childhood overweight and obesity. Int J Pediatr Obes 2006;1:1125. https://doi.org/10.1080/17477160600586747

6. Çatlı G, Erdem P, Anık A, Abacı A, Böber E. Clinical and laboratory findings in the differential diagnosis of central precocious puberty and premature thelarche. Turk Pediatri Ars 2015;50:20-26. https://doi.org/10.5152/ tpa.2015.2281

7. Bratberg GH, Nilsen TI, Holmen TL, Vatten LJ. Early sexual maturation, central adiposity and subsequent overweight in late adolescence, a four-year follow-up of 1605 adolescent Norwegian boys and girls: the Young HUNT study. BMC Public Health 2007;7:54. https://doi. org/10.1186/1471-2458-7-54

8. Yue ZHAO, Ling HOU, Hong-jie GAO, Di ZHAN, Cai ZHANG, Xiao-ping LUO. Independent relationship between body mass index and $\mathrm{LH}$ peak value of $\mathrm{GnRH}$ stimulation test in ICPP Girls: a cross-sectional study. J Huazhong Univ Sci Technol 2017;37:556-562. https:// doi.org/10.1007/s11596-017-1772-2

9. Marshall WA, Tanner JM. Variations in pattern of pubertal changes in girls. Arch Dis Childh 1969;44:291-303. https://doi.org/10.1136/adc.44.235.291

10. Bundak R, Furman A, Gunoz H, Darendeliler F, Bas F, Neyzi O. Body mass index references for Turkish children. Acta Paediatr 2006;95:194-198. https://doi. org/10.1111/j.1651-2227.2006.tb02206.x

11. Neyzi O, Gunoz H, Furman A, et al. Weight, height, head circumference and body mass index references for Turkish children. Cocuk Sağlığı ve Hastalıkları Dergisi 2008;51:1-14.

12. Greulich WW PS. Radiologic atlas of skeletal development of the hand and wrist. . 2 ed. Standford (CA): Stanford University Press 1959.

13. Lee HS, Park HK, Ko JH, Kim YJ, Hwang JS. Utility of Basal luteinizing hormone levels for detecting central precocious puberty in girls. Horm Metab Res 2012;44:851-854. https://doi. org/10.1055/s-0032-1321905 
14. Carel JC, Eugster EA, Rogol A, et al. Consensus statement on the use of gonadotropin-releasing hormone analogs in children. Pediatrics 2009;123:752762. https://doi.org/10.1542/peds.2008-1783

15. Kaplowitz PB, Slora EJ, Wasserman RC, Pedlow SE, Herman-Giddens ME. Earlier onset of puberty in girls: relation to increased body mass index and race. Pediatrics 2001;108:347-353. https://doi.org/10.1542/ peds.108.2.347

16. Atay Z, Turan S, Guran T, Furman A, Bereket A. The prevalence and risk factors of premature thelarche and pubarche in 4- to 8-year-old girls. Acta Paediatr 2012;101:71-75. https://doi.org/10.1111/j.16512227.2011.02444.x

17. de Leonibus C, Marcovecchio ML, Chiavaroli V, de Giorgis T, Chiarelli F, Mohn A. Timing of puberty and physical growth in obese children: a longitudinal study in boys and girls. Pediatr Obes 2014;9:292-299. https:// doi.org/10.1111/j.2047-6310.2013.00176.x

18. Sopher AB, Jean AM, Zwany SK, et al. Bone age advancement in prepubertal children with obesity and premature adrenarche: possible potentiating factors. Obesity (Silver Spring) 2011;19:1259-1264. https://doi. org/10.1038/oby.2010.305

19. De Simone M, Farello G, Palumbo M, et al. Growth charts, growth velocity and bone development in childhood obesity. Int J Obes Relat Metab Disord 1995; 19:851-857.

20. Shalitin S, Kiess W. Putative effects of obesity on linear growth and puberty. Horm Res Paediatr 2017;88:101110. https://doi.org/10.1159/000455968

21. Russell DL, Keil MF, Bonat SH, etal. The relation between skeletal maturation and adiposity in African American and Caucasian children. J Pediatr 2001;139:844-848. https://doi.org/10.1067/mpd.2001.119446

22. Johnson W, Stovitz SD, Choh AC, et al. Patterns of linear growth and skeletal maturation from birth to 18 years of age in overweight young adults. Int $\mathrm{J}$ Obes (Lond) 2012;36:535-541. https://doi.org/10.1038/ ijo.2011.238

23. Stovitz SD, Demerath EW, Hannan PJ, Lytle LA, Himes $\mathrm{JH}$. Growing into obesity: patterns of height growth in those who become normal weight, overweight, or obese as young adults. Am J Hum Biol 2011;23:635641. https://doi.org/10.1002/ajhb.21191

24. Klein KO, Newfield RS, Hassink SG. Bone maturation along the spectrum from normal weight to obesity: a complex interplay of sex, growth factors and weight gain. J Pediatr Endocrinol Metab 2015;29:311318. https://doi.org/10.1515/jpem-2015-0234.

25. Klein KO, Larmore KA, de Lancey E, Brown JM, Considine RV, Hassink SG. Effect of obesity on estradiol level, and its relationship to leptin, bone maturation, and bone mineral density in children. $J$ Clin Endocrinol Metab 1998;83:3469-3475. https://doi. org/10.1210/jcem.83.10.5204
26. Ahmed ML, Ong KK, Dunger DB. Childhood obesity and the timing of puberty. Trends Endocrinol Metab 2009;20:237-242. https://doi.org/10.1016/j. tem.2009.02.004

27. Fu JF, Liang JF, Zhou XL, et al. Impact of BMI on gonadorelin-stimulated $\mathrm{LH}$ peak in premenarcheal girls with idiopathic central precocious puberty. Obesity 2015,23:637-643. https://doi.org/10.1002/oby.21010

28. Giabicani E, Allali S, Durand A, et al. Presentation of 493 consecutive girls with idiopathic central precocious puberty: a single-center study. PLoS One 2013;8:709731. https://doi.org/10.1371/journal.pone.0070931

29. Bordini B, Littlejohn E, Rosenfield RL. LH Dynamics in Overweight Girls with premature adrenarche and slowly progressive sexual precocity. Int J Pediatr Endocrinol 2010;2010:724696. https://doi. org/10.1155/2010/724696

30. McCartney CR, Prendergast KA, Blank SK, Helm KD, Chhabra S, Marshall JC. Maturation of luteinizing hormone (gonadotropin-releasing hormone) secretion across puberty: evidence for altered regulation in obese peripubertal girls. J Clin Endocrinol Metab 2009;94:5666. https://doi.org/10.1210/jc.2008-1252

31. Lee HY, Lee YJ, Ahn MB, Cho WK, Suh BK. The effect of overweight on the luteinizing hormone level after gonadorelin stimulation test in girls with idiopathic central precocious puberty. Ann Pediatr Endocrinol Metab 2018;23:215-219. https://doi.org/10.6065/ apem.2018.23.4.215

32. Lee HS, Yoon JS, Hwang JS. Luteinizing hormone secretion during gonadotropin-releasing hormone stimulation tests in obese girls with central precocious puberty. J Clin Res Pediatr Endocrinol 2016;8:392-398. https://doi.org/10.4274/jcrpe.3091

33. Roth LW, Bradshaw-Pierce EL, Allshouse AA, Lesh $\mathrm{J}$, Chosich J, Bradford AP, et al. Evidence of GnRH antagonist escape in obese women. J Clin Endocrinol Metab 2014;99:871-875. https://doi.org/10.1210/ jc.2013-3598

34. Leung KC, Johannsson G, Leong GM, Ho KK. Estrogen regulation of growth hormone action. Endocr Rev 2004;25:693-721. https://doi.org/10.1210/er.20030035

35. Rosenfield RL, Fang VS. The effects of prolonged physiologic estradiol therapy on the maturation of hypogonadal teen-agers. J Pediatr 1974;85:830-837. https://doi.org/10.1016/S0022-3476(74)80355-0

36. Wennink JM, Delemarre-van de Waal HA, Schoemaker $\mathrm{R}$, Schoemaker $\mathrm{H}$, Schoemaker J. Luteinizing hormone and follicle stimulating hormone secretion patterns in girls throughout puberty measured using highly sensitive immunoradiometric assays. Clin Endocrinol (Oxf) 1990;33:333-344. https://doi. org/10.1111/j.1365-2265.1990.tb00498.x 
37. de Groot CJ, van den Berg A, Ballieux BE, et al. Determinants of advanced bone age in childhood obesity. Horm Res Paediatr 2017;87:254-263. https:// doi.org/10.1159/000467393

Etik onayı: Çalışma, Behçet Uz Çocuk Hastanesi Tıbbi Etik Komitesi tarafından onaylandı. 